\title{
Anthony Aveni, Star Stories: Constellations and People
}

New Haven and London: Yale University Press, 2019. Hardback, 194 pages. ISBN: 978-0-300-24128-0. £20.00.

\section{H. Natalia Sánchez}

University of Wales Trinity Saint David

hnsanchezs@unal.edu.co

Star Stories explores a wide variety of myths, tales and more contemporary narratives around stars and the different asterisms and constellations created from them by diverse cultures around the globe. The book was written as its American author, Anthony Aveni, was entering his eighties, and it is infused with his extensive knowledge and experience as an astronomer and anthropologist, and as one of the founders of the field of cultural astronomy.

The work is intended to be a "casual conversation" (p. 181), so it is mainly focused on a wide audience. As such, each chapter is preceded by a picture by the British illustrator Matthew Green, and there are many other visual aids that enrich the tales and situate the reader. This gives the piece a non-academic feel while maintaining a smooth academic voice: thereby easy-to-read, scholarly supported and enjoyable.

This approach shows that there is a treasure to be unveiled through its reading, revealed at the very end, in the epilogue. Aveni's aim, then (spoiler alert), is to show through a variety of cosmic stories that non-analytic and non-rational ways of understanding nature are valuable and meaningful. He argues that the religious and social backgrounds of different cultures contribute to give meaning to the storytelling of the shiny dots viewed in the night sky. So, to comprehend and appreciate a society's astronomical knowledge, he argues that we need to open up our modern scientific thought to other ways of understanding - the "sky-as-a-social-field approach" as proposed by Stanislaw Iwaniszewski $(2011,36)$. Aveni wants to share these ideas with the general public while reinforcing the message within the scholarly arena.

The book starts with a preface and introduction that situates the reader for what is going to be told - a variety of stories from different places on Earth about selected constellations and asterisms that act as a heavenly discourse about "moral issues and social rules" (p. 4); as such, the coverage excludes the Sun, the Moon, the planets and 
other heavenly bodies. This is followed by five of ten chapters that gather the most common and popular of the stellar groupings: Orion, the Pleiades, various zodiacs and the light and dark areas of the Milky Way. Aveni then brings in other not-so-familiar star patterns, such as the ones that can be seen at the North Pole and those visible from the tropics (chapters 6 and 7). These seven chapters present narratives from all the continents, although Europe has only a few representatives while North America has a lot; his coverage includes ancient societies such as those of Egypt, Greece and China, the Aztecs of Mesoamerica and living traditional cultures such as those of Barasana, Inuit, Lakota and Maori societies. The different myths and tales told in these chapters show that stars are, or represent, gods, humans, animals and natural or human-made objects, and that the narratives relate to weather prediction, ethical codes, social issues, natural rhythms, navigation techniques and time and space markers.

The three final chapters bring a new scent to the work, by not focusing on certain constellations and their corresponding stories but on how stars in general have been represented and what their role is in the cosmologies of various societies. Chapter 8 discusses how celestial lore is used in leadership, politics and the planning and construction of houses and cities, through specific examples. Chapter 9 focuses on gigantic constellations and star ceilings, while chapter 10 describes how societies gender the skies by assigning male and female roles to the stars, and the purposes behind this.

Aveni concludes with a short epilogue followed by a "bibliographic essay" (yes, references by chapter and written as an essay), acknowledgements and a detailed index. These three last sections show again that the book wants to approach both academic and non-academic audiences. The bibliography is detailed enough to give scholarly readers the sources of direct quotes and where the stories came from. But Aveni does not restrict the references to items used directly; he gives the reader other sources to expand on certain subjects and even recommends books for children. This section also helps the general public to become more contextualised on certain themes, as for some chapters there are sentences or even whole paragraphs intended to explain further and give more details. In my opinion, I would have preferred to have these elements within the main text to get the most out of them, rather than in a bibliographic and separate section which felt unconnected to the rest of the book.

As can be inferred by scholars in cultural astronomy, Aveni has brought diverse elements of the field into his account. Although not directly addressed, he uses archaeoastronomical, historic and ethnographical studies to build his arguments. At first sight, I must confess that I thought the work would be myth oriented, but he managed to exceed my expectations - even though the language used in the historical narratives sometimes presents links between particular stars and characters as established when in fact there is no primary source available that explicitly states this as such. For example, Aveni presents the three glyphs on the back of the Maya turtle as Orion's Belt (pp. 15, 62), although there is no unanimity among Maya experts. When I researched the Orion constellation in Mayan cosmology, I found that scholars agree that the cosmic turtle represents Orion, but only some specify that the three glyphs correspond to the famous belt (Pincemin Deliberos 1998, 132; Milbrath 1999, 253; Velásquez et al. 2011, 140). Aveni is successful in 
bringing a multitude of heavenly stories to enrich the book, but sometimes he relies on only one or two sources. It would have been better to state from the beginning that some details of the stories are just possible interpretations, rather than present them as fact, or to have adjusted the language when there is doubt. Even so, the message is delivered magnificently and Aveni's aim has been brilliantly accomplished, regardless not being explicit with regard to the scholarly certainty of some specific details.

Another minor issue is that Aveni assumes that the reader is knowledgeable about the American tribes of North America. Every time he introduces a culture from elsewhere, he tries to situate the reader at least with a geographical location. But, when referring to the Iroquois, Ojibwa, Pawnee and others, he does not specify their location. This can make the reader feel lost if one does not know about Native American communities.

If you are a curious reader and interested in the scientific side of astronomy you will have the nice surprise that when it is needed, Aveni takes the time to explain the movements of the stars in a particular location for you to understand better why the narratives make sense. Helped by illustrations, you can visualise what is or was imagined by the peoples that created the stories. Nevertheless, I felt that there could have been more illustrations to aid non-specialist readers who are not aware of how a certain constellation is configured and where there are other nearby asterisms. You will find that the key constellations or asterisms always have a helpful image but that stories usually interact with other stars or groupings that were not always visually represented in the book. My recommendation for this is to have a celestial map to hand.

Despite the minor difficulties described, the book is admirably written and designed. It opens the mind to other kinds of thinking, to unknown places and cultures that challenge the usual Greek and Roman narratives about the sky. On the one hand, it is very helpful for scholars studying cultural astronomy, because it opens a breadth of mythical perspectives about the stars and introduces literature from all around the world; and on the other, it is breathtaking, highly entertaining and understandable for non-specialist readers, who will be amazed by the great variety of tales that the book addresses. Overall, an excellent book that shows nicely that "every star story is about us" (p. 165).

\section{References}

Iwaniszewski, S., 2011. "The Sky as a Social Field". In "Oxford IX" International Symposium on Archaeoastronomy, edited by C. L. N. Ruggles, 30-37. Cambridge: Cambridge University Press. https://doi.org/10.1017/ S1743921311012440

Milbrath, S., 1999. Star Gods of the Maya: Astronomy in Art, Folklore, and Calendars. Austin: University of Texas Press.

Pincemin Deliberos, S., 1998. “Constelaciones y Danzantes: Dos nuevos dibujos de los murales de Bonampak". In La Pintura Mural prehispánica en México, vol. 2: Área Maya: Bonampak, vol. 2: Estudios, edited by B. de la Fuente, 131-135. México: Universidad Nacional Autónoma de México [online]. Accessed July 2020. http://132.248.9.195/libroe_2007/0931807_5/Index.html

Velásquez García, E., J. Galindo Trejo and S. Iwaniszewski 2011. "Capítulo VIII. La Astronomía". In Los Mayas, Voces de Piedra, edited by A. Martínez de Velasco and M. E. Vega, 127-150. México: AmbarDiseño. 